\title{
Article \\ Optimizing Operating Parameters of Electric Ultra-Low Volume Sprayer with Slightly Acidic Electrolyzed Solution for Efficient Virucidal Activity on Environmental Surfaces
}

\author{
Hae-Won Lee, So-Ra Yoon, Hyeyeon Song, Boyeon Park and Ji-Hyoung Ha *D
}

check for updates

Citation: Lee, H.-W.; Yoon, S.-R.; Song, H.; Park, B.; Ha, J.-H. Optimizing Operating Parameters of Electric Ultra-Low Volume Sprayer with Slightly Acidic Electrolyzed Solution for Efficient Virucidal Activity on Environmental Surfaces. Int. J. Environ. Res. Public Health 2021, 18, 10183. https://doi.org/10.3390/ ijerph181910183

Academic Editor: Kow-Tong Chen

Received: 18 August 2021

Accepted: 26 September 2021

Published: 28 September 2021

Publisher's Note: MDPI stays neutral with regard to jurisdictional claims in published maps and institutional affiliations.

Copyright: (c) 2021 by the authors. Licensee MDPI, Basel, Switzerland. This article is an open access article distributed under the terms and conditions of the Creative Commons Attribution (CC BY) license (https:// creativecommons.org/licenses/by/ $4.0 /)$.
Hygienic Safety and Analysis Center, World Institute of Kimchi, Gwangju 61755, Korea; lhw0875@wikim.re.kr (H.-W.L.); sorayoon@wikim.re.kr (S.-R.Y.); danbihy@wikim.re.kr (H.S.); boyeonpark@wikim.re.kr (B.P.)

* Correspondence: hajee@wikim.re.kr; Tel.: +82-62-610-1845

Abstract: Recently, and considering the COVID-19 pandemic, there has been a growing consensus that the disinfection of surfaces contaminated with pathogenic viral particles is essential. Chemical disinfectant sprays are effective at preventing the spread of infectious human noroviruses (Hu-NoVs) in healthcare and public areas. We assessed the virucidal activity of slightly acidic electrolyzed water (SAEW) spray on fomite surfaces. A multivariate statistical assessment that combined a response surface methodology (RSM) and a Box-Behnken design (BBD) was performed to define the optimal parameters of, and correlations among, experimental conditions. Spraying SAEW disinfectant (oxidation-reduction potential: $1123 \mathrm{mV}$, $\mathrm{pH}$ range: 5.12, available chlorine concentration: $33.22 \mathrm{ppm}$ ) resulted in the successful decontamination of $\mathrm{Hu}-\mathrm{NoV}$, with a 4-log reduction in viral particles on polyvinyl chloride, stainless steel, ceramic tile, and glass surfaces. Our experimental data revealed optimized treatment conditions for decontaminating Hu-NoV GI.6 and GII.4, using the numerical multiple optimized method (spraying rate: $218 \mathrm{~mL} / \mathrm{min}$, spraying time: $4.9 \mathrm{~s}$, spraying distance: $0.9 \mathrm{~m}$ ). These findings offer significant insights for designing optimal strategic control practices to prevent infectious disease, particularly $\mathrm{Hu}-\mathrm{NoV}$, transmission.

Keywords: human norovirus; optimization; response surface methodology; slightly acidic electrolyzed water; spray disinfection

\section{Introduction}

Human noroviruses (Hu-NoVs), characterized by high infectivity among humans, short-term immunity, tenacious environmental persistence, and high viral load excretion, cause sporadic cases of nonbacterial gastroenteritis and represent the most significant etiologic agent of human epidemics, regardless of age or sex, and likely owing to their hightransmissibility across industrialized nations [1]. Moreover, the Centers for Disease Control and Prevention (CDC) reported that, annually, $\mathrm{Hu}-\mathrm{NoV}$ infections cause an estimated 200,000 deaths, with more than 590,000,000 cases worldwide [2].

Historically, gastrointestinal viral pathogens have been shown to be readily transmitted via waterborne or environmental fomite routes, direct person-to-person transmission, or the fecal-oral route [3]. However, more recently, airborne viral pathogens, including those in aerosolized droplets (e.g., $\mathrm{Hu}-\mathrm{NoVs}$ ) have been proven to be particularly hazardous. In fact, previous studies have asserted that aerosolized Hu-NoV particles, produced by carrier patients, represent a significant source of transmission [4,5]. Bonifait et al. demonstrated that viral droplets can be aerosolized from infected gastrointestinal bodily fluids, including feces or vomit, which can become deposited in the upper respiratory tract during inhalation and subsequently swallowed; alternatively, these aerosolized particles can become attached to the surface of environmental fomites [6]. In the case of infectious $\mathrm{Hu}-\mathrm{NoVs}$, viral particles on environmental surfaces often serve as the epicenter of sec- 
ondary cross-contamination. In fact, several studies have investigated the $\mathrm{Hu}-\mathrm{NoV}$ particle contamination of common surfaces in airplane cabins, as well as in hospital air sources during outbreaks, via RNA quantification [7]. Importantly, Bonifait et al. reported that murine norovirus-1 (MNV-1) acts as a surrogate for $\mathrm{Hu}-\mathrm{NoVs}$, remaining infectious even after aerosolization, resulting in viable $\mathrm{Hu}-\mathrm{NoV}$ particles attaching to environmental surfaces and that are capable of infecting individuals [6]. Indeed, the secondary contamination of surfaces by Hu-NoVs represents a significant route of infection, owing to their low infectious dose, long-term environmental persistence, and shedding by infected individuals.

The primary factors responsible for the bactericidal activity of slightly acidic electrolyzed water (SAEW) appear to be the presence of a high oxidation-reduction potential (ORP), the free available chlorine content (ACC), as well as the presence of hypochlorous acid $(\mathrm{HOCl})$ and hypochlorite ions (OCl-) [8]. SAEW is generated by electrolyzing an aqueous solution of hydrochloric acid $(\mathrm{HCl})$ or $\mathrm{NaCl}$ using a non-membrane electrolytic cell. The efficient form of free available chlorine compounds in SAEW is typically $\mathrm{HOCl}$, with strong bactericidal efficacy in a $\mathrm{pH}$ range of 5.0-6.5 [8]. SAEW exhibits broad-spectrum antimicrobial effectiveness against a range of microorganisms, including non-enveloped viruses such as Hu-NoVs. Thus, the virucidal activities of SAEW against cultivable HuNoV surrogates (e.g., MNV) and Hu-NoV GII.4 Sydney in solution have been evaluated in several studies [9]. In spite of the widespread application and established effectiveness of SAEW against pathogenic microbials, there has not been a sufficient number of studies performed to assess its ability to decontaminate surfaces exposed to Hu-NoVs. This is largely owing to the fastidiousness of the reliable detection and quantitative assays for $\mathrm{Hu}-\mathrm{NoV}$ s, based on RNA viability. To achieve a precise qualitative and quantitative analysis, Lee et al. demonstrated that the application of a magnetic bead separation (MBS) assessment combined with an intercalating dye, such as propidium monoazide (PMA), and reverse transcription-quantitative polymerase chain reactions (RT-qPCR) successfully and selectively detects viral particles, while distinguishing between intact and damaged particles [10]. Additionally, anionic surfactant treatments (e.g., sodium lauroyl sarcosinate (SLS) [11] assist the penetration of inactivated viral capsids by PMA, thereby enhancing the distinction between noninfectious and infectious viruses. Hence, a combination of these techniques has the capacity to enhance the precise quantification of intact $\mathrm{Hu}-\mathrm{NoVs}$ on environmental surfaces following exposure to chemical disinfectants.

Recently, among the various strategies for eliminating viral particles as human infection sources from environmental fomites, the spraying of chemical agents has proven successful for preventing the spread of infectious $\mathrm{Hu}-\mathrm{NoV}$ s in healthcare and the public sector [12]. A significant advantage of spraying disinfectants in a mist from a machine is the dispersion effect achieved, facilitating the capture of airborne pathogens prior to rapidly settling on surfaces [13]. Hence, this strategy ensures that no chemical particles remain in the air after spraying the disinfectant, thus limiting the risk of inhalation by those administering the spray. Furthermore, this spraying technique has been applied in food industrial fields for the disinfection of fresh vegetables and fruits or the decontamination of surfaces in process lines and working areas [14]. According to the CDC [15], however, further research is required to verify the efficacy of chemical spraying for the elimination of $\mathrm{Hu}-\mathrm{NoV}$ contamination. Specifically, more in-depth data are required to determine the optimal surface contact range for disinfectant sprays. Moreover, although many studies have been conducted with various chemical sprays, little is known regarding the optimum spraying treatments for the disinfection of Hu-NoVs using SAEW $[16,17]$.

The specific objective of this study was to investigate the optimum virucidal activities with a SAEW spraying treatment on various inanimate surfaces. Moreover, a multivariate statistical assessment using a combination of response surface methodology (RSM) and a Box-Behnken design (BBD) was employed to define the optimal parameters and correlation between experimental data, including the process time, flow rate, and spray distance. 


\section{Materials and Methods}

\subsection{Viruses}

Hu-NoV genogroup-I genotype-6 (Hu-NoV GI.6) and genogroup-II genotype-4 (HuNoV GII.4) were provided by the Waterborne Virus Bank (Seoul, Korea). In this study, the initial titer of Hu-NoV GI.6 and GII.4 suspension samples for virucidal effect test was approximately between 5.0 and $5.5 \log 10$ genomic copies $/ 500 \mu \mathrm{L}$. For the disinfection test, all $\mathrm{Hu}-\mathrm{NoV}$ stock were prepared using $500 \mu \mathrm{L}$ of the $\mathrm{Hu}-\mathrm{NoV}$ sample. To prepare the virucidal test mixture, Hu-NoV $(100 \mu \mathrm{L})$ was vortexed briefly with $400 \mu \mathrm{L}$ of RNase-free water. Approximately $500-\mu \mathrm{L}$ aliquots of the solution were stored at $-80{ }^{\circ} \mathrm{C}$.

\subsection{Preparation of SAEW and SAEW Spraying Machine}

SAEW was generated via electrolysis of $5.5 \%$ hydrochloric acid in a chamber without a membrane using electrolyzed water equipment (Purester m-Clean; Morinaga Engineering Co., Ltd., Tokyo, Japan) at a setting of $2.45 \mathrm{~A}$ and $21.5 \mathrm{~V}$. The $\mathrm{pH} / \mathrm{ORP}$ values of the SAEW solution were measured using a dual-scale $\mathrm{pH}$ meter (Accumet model 25; Fisher Scientific Co., Fair Lawn, NJ, USA) equipped with ORP/pH electrodes. The production rate of SAEW solution was reached at a $9.8 \mathrm{~L} / \mathrm{min}$ flow rate. The colorimetric method, using a digital chlorine test kit (RC-3F; Kasahara Chemical Instruments Corp., Saitama, Japan), was used to measure the ACC of SAEW. The initial SAEW had an ORP of $1123 \mathrm{mV}$, ACC of $33.22 \mathrm{ppm}$, and $\mathrm{pH}$ of 5.12. The prepared SAEWs were used immediately for analyses. The ORP, ACC, and pH of SAEW were measured in triplicate before the experiment. An electric ultra-low volume (ULV) sprayer (Atomer-2 RA04HS, JY Industry co, Seoul, Korea) was used to generate sprayed SAEW droplets (droplet size: 20-50 $\mu \mathrm{m}$; maximum discharge capacity: $1.2 \mathrm{~L} / \mathrm{min})$.

\subsection{Experimental Design of SAEW Spray Treatment Using an Electric ULV Sprayer}

\subsubsection{Box-Behnken Design}

RSM statistical analysis was conducted to determine correlations among experimental parameters and to determine the optimal parameters for spraying disinfectants to effectively decontaminate Hu-NoVs. The optimized experimental design was performed using BBD combined with RSM, as defined by Myers and Montgomery [18]. The study variables were the spraying rate, spraying time, and spraying distance for SAEW against Hu-NoVs. The experimental design using BBD, which is regarded as the most reliable design method, was conducted using the Minitab statistical software, version 20 (Systat Software Inc., San Jose, CA, USA). Herein, we selected three BBD levels. The three levels of BBD comprised a set of points located at the midpoint of each end and the replicated central point of the multidimensional cube to gain the second-order polynomial regression models. Individual variable experiments were designed to express the independent treatment conditions of spraying rate (100-300 mL/min), spraying time (2-10 s), and spraying distance $(0.5-2.5 \mathrm{~m})$. The three independent parameters were investigated at three levels: +1 , high level; 0 , midpoint to determine experimental error; -1 , low level (Table 1).

Table 1. Box-Behnken design matrix parameters and levels used to assess slightly acidic electrolyzed water spraying disinfection conditions.

\begin{tabular}{ccccc}
\hline \multirow{2}{*}{ Parameter } & Symbol & \multicolumn{3}{c}{ Levels } \\
\cline { 3 - 5 } & & Low (-1) & Intermediate (0) & High (+1) \\
\hline $\begin{array}{c}\text { Spraying rate } \\
(\mathrm{mL} / \text { min) }\end{array}$ & $\mathrm{X}_{1}$ & 100 & 200 & 300 \\
$\begin{array}{c}\text { Spraying time (s) } \\
\text { Spraying }\end{array}$ & $\mathrm{X}_{2}$ & 2 & 6 & 10 \\
distance (m) & $\mathrm{X}_{3}$ & 0.5 & 1.5 & 2.5 \\
\hline
\end{tabular}


To determine the efficacy of the three independent parameters on the SAEW spraying treatment for $\mathrm{Hu}-\mathrm{NoV}$ decontamination, a quadratic regression model, as presented in Equation (1), was applied:

$$
Y=\beta_{0}+\sum_{i=1}^{k} \beta_{i} X_{i}+\sum_{i=1}^{k} \beta_{i i} X_{i}^{2}+\sum_{i=1}^{k} \sum_{j>1}^{k} \beta_{i j} X_{i} X_{j}+\varepsilon .
$$

where $X_{i}$ and $X_{j}$ represent coded independent variables; $Y$ is the response; $\beta_{0}, \beta_{i}, \beta_{i i}$, and $\beta_{i j}$ are the constant coefficients of intercept, linear, interaction, and quadratic terms, respectively; and $\varepsilon$ represents the error. The regression model significance was determined based on the adjusted coefficient of determination ( $R^{2}$ adj). Its statistical significance was verified with ANOVA, coefficient of multiple determination $\left(R_{2}\right)$, Fisher's F test, and the lack of fit test in Minitab software. The 3D graphical plots of the Minitab software behavior, which was defined by the response surface, were used to describe the effective dispersion of SAEW spray droplets and the efficiency of the contact ratio to the target surface area.

\subsubsection{Analysis of the Dispersion Pattern of SAEW Sprayed Particles}

To identify the dispersion and contact pattern of SAEW spray droplets via a computational system, an analytical technique based on a colorimetric sensing image, combined with pattern-recognition methods, was used (Figure 1).

Food-grade citric acid (Sigma-Aldrich, St. Louis, MO, USA) was added to lower the $\mathrm{pH}$ of the SAEW solution. The mixture increased the sensitivity of the $\mathrm{pH}$-sensitive indicator (Universal $\mathrm{pH}$ Paper, Waterloo, ON, Canada) response. SAEW with citric acid and a $\mathrm{pH}$-sensitive indicator was used to confirm the dispersion pattern of SAEW fogged droplets emitted from the electric ULV sprayer in the open atmosphere and to compare the relative quantitative values of SAEW in contact with the target surface, according to the spray conditions.

First, colorimetric sensor imaging was performed on SAEW spray-treated $\mathrm{pH}$-sensitive indicator paper, which was placed in the open-frame stage of an online monitoring system coupled with NIS-Element software, which was developed for this work (Figure 1). One sheet of $\mathrm{pH}$-sensitive indicator paper was positioned and fixed vertically on a laboratory workbench. The SAEW sprayer was activated according to the designated experimental conditions. The experimental treatment conditions, as designated by the BBD (Table 1), are shown in Table 2.

Table 2. Three-parameter BBD matrix with predicted and observed color response values $\left(\mathrm{F}\left(\mathrm{X}_{\mathrm{C}}\right)\right)$.

\begin{tabular}{ccccccccc}
\hline \multirow{2}{*}{ Run } & \multicolumn{3}{c}{ Coded Value } & \multicolumn{3}{c}{ Actual Value } & \multicolumn{2}{c}{$F\left(\boldsymbol{X}_{C}\right)$} \\
\cline { 2 - 9 } & $\boldsymbol{X}_{\mathbf{1}}$ & $\boldsymbol{X}_{\mathbf{2}}$ & $\boldsymbol{X}_{\mathbf{3}}$ & $\boldsymbol{X}_{\mathbf{1}}$ & $\boldsymbol{X}_{\mathbf{2}}$ & $\boldsymbol{X}_{\mathbf{3}}$ & Observed & Predicted \\
\hline 1 & 0 & 0 & 0 & 200 & 6 & 1.5 & 1.36 & 1.38 \\
2 & 0 & -1 & 1 & 200 & 2 & 2.5 & 0.68 & 0.49 \\
3 & -1 & 0 & -1 & 100 & 6 & 0.5 & 0.96 & 0.81 \\
4 & 0 & 1 & 1 & 200 & 10 & 2.5 & 0.31 & 0.33 \\
5 & 1 & 0 & 1 & 300 & 6 & 2.5 & 0.12 & 0.25 \\
6 & 1 & -1 & 0 & 300 & 2 & 1.5 & 0.83 & 0.87 \\
7 & -1 & -1 & 0 & 100 & 2 & 1.5 & 0.80 & 0.96 \\
8 & -1 & 1 & 0 & 100 & 10 & 1.5 & 0.73 & 0.68 \\
9 & 0 & -1 & -1 & 200 & 2 & 0.5 & 1.12 & 1.09 \\
10 & 0 & 1 & -1 & 200 & 10 & 0.5 & 0.99 & 1.17 \\
11 & 0 & 0 & 0 & 200 & 6 & 1.5 & 1.06 & 1.17 \\
12 & -1 & 0 & 1 & 100 & 6 & 2.5 & 0.36 & 0.37 \\
13 & 1 & 0 & -1 & 300 & 6 & 0.5 & 1.27 & 1.25 \\
14 & 1 & 1 & 0 & 300 & 10 & 1.5 & 1.25 & 1.08 \\
15 & 0 & 0 & 0 & 200 & 6 & 1.5 & 1.19 & 1.21 \\
\hline
\end{tabular}


(a) Experimental research

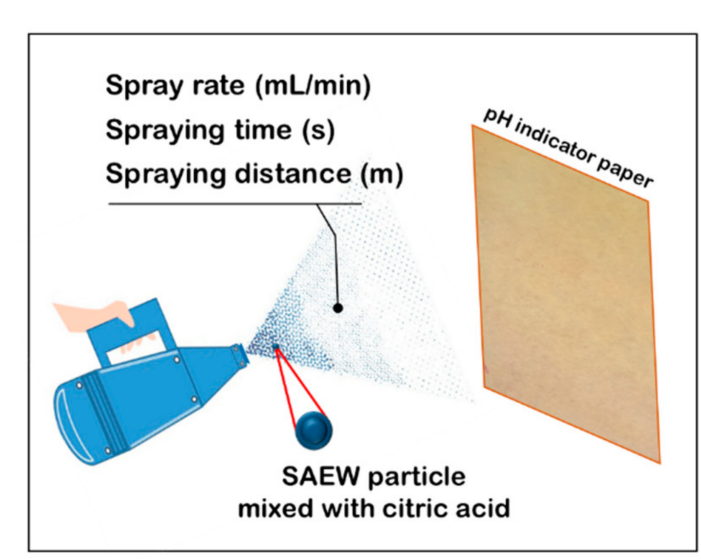

(b) The colorimetric response patterns of $\mathrm{pH}$ indicators

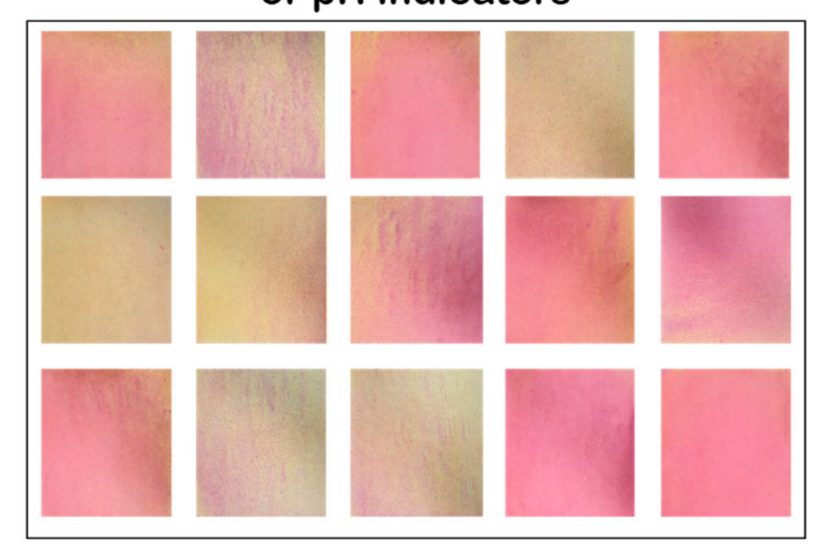

(c) Data processing

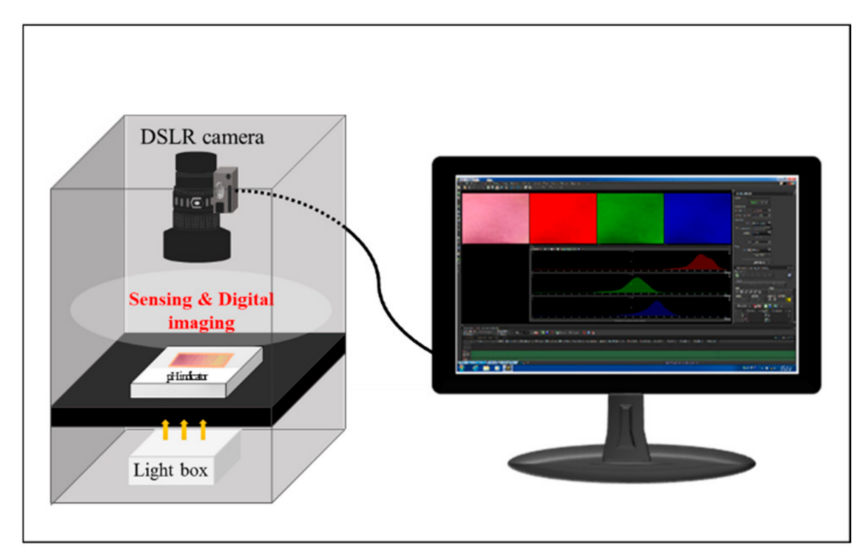

\section{Colorimetric sensor imaging technique}

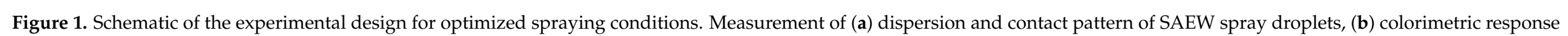
patterns of $\mathrm{pH}$ indicators, and (c) SAEW spray droplets via a computational system. 


\subsubsection{Kinetic Parameters of the $\mathrm{pH}-$ Sensitive Indicator}

$L^{*}, a^{*}$, and $b^{*}$ values for the color changes of the SAEW spray-treated $\mathrm{pH}$-sensitive indicator paper were obtained using a CR-420 chromameter (Konica Minolta, Osaka, Japan). According to Giannakourou and Taoukis [19], based on the Hunter $L, a$, and $b$ color, the chroma values were determined to efficiently quantify the total color difference of the $\mathrm{pH}$-sensitive indicator, using the chroma value equation (Equation (2)):

$$
C=\sqrt{\left(a^{*}\right)^{2}+\left(b^{*}\right)^{2}}
$$

Giannakourou and Taoukis [19] demonstrated that the normalized chroma value $\left(X_{C}\right)$ could be used as the response $X$ of the colorimetric indicator, which, when plotted as a function of time, had a sigmoidal shape, similar to a Gaussian function (determined as $\left.X=1-\exp \left[-(k t)^{2}\right]\right)$. The normalization of the chroma value equation (Equation (3)) was expressed as follows:

$$
X_{C}=\frac{\left(C-C_{\min }\right)}{\left(C_{\max }-C_{\min }\right)}
$$

Finally, the color response values of the $\mathrm{pH}$-sensitive indicators were expressed using the following linearized response equation (Equation (4)):

$$
F\left(X_{C}\right)=\sqrt{\ln \left[\frac{1}{\left(1-X_{C}\right)}\right]}
$$

where $\mathrm{F}\left(X_{C}\right)$ indicates the color response value.

\subsubsection{Pressure Distribution Measurement System}

The pressure distribution, which corresponded to the spraying rate of the ULV sprayer set in this study, was measured using a large area flexible pressure-sensing integrated circuit (IC) board (Snowboard, $1.7 \mathrm{~mm} \times 1.7 \mathrm{~mm}$, Kitronyx Corp, Seoul, Korea). The Snowboard, a tactile sensor array, is an Arduino Leonardo-compatible board with integrated spray pressure and contact-sensor controllers. The spray pressure-sensing IC and Snowboard software (ForceLAB software, Kitronyx Corp) enabled visualization of the pressure load in any resistive matrix sensor. For the air pressure distribution measurement, the distance between the sensor and the nozzle of the electric ULV sprayer was $30 \mathrm{~cm}$, while the average observed value of the experimental data acquired in real time was derived from pressure distribution, measuring for $1 \mathrm{~min}$.

\subsection{Surface Materials}

In this study, various environmental surfaces were examined to determine the optimal spraying rate, spraying time, and spraying distance for $\mathrm{Hu}-\mathrm{NoV}$ decontamination using the SAEW sprayer The four material types were polyvinyl chloride (PVC) (HDPE; Hangiltech Co., Seoul, Korea), stainless steel (Hyundai BNG steel, SUS-ANSI 306, Seoul, Korea), ceramic tile (Hankook Chinaware Co., Ltd., Seoul, Korea), and glass (SeoulYuri, Seoul, Korea), which are representative materials of most environmental fomites. Sheets of the four types of material were cut into $10 \mathrm{~cm} \times 10 \mathrm{~cm}$ pieces. Prepared surface materials were disinfected by immersing them thoroughly in 50,000 ppm sodium hypochlorite, washing with sterilized water in an Ultrasonic Cleaner (Sigma-Aldrich) for $5 \mathrm{~min}$, and rinsing with deionized water. Each dried plate sheet was then wrapped with UV radiation-treated aluminum foil, placed in a glass beaker, and autoclaved at $121^{\circ} \mathrm{C}$ prior to the experiment.

\subsection{Evaluation of the Virucidal Activity of SAEW Sprayed Droplets}

Approximately $200 \mu \mathrm{L}$ each of the two Hu-NoV suspensions was mixed with $190 \mu \mathrm{L}$ of phosphate-buffered saline (PBS, pH 7.5, Sigma-Aldrich) and $10 \mu \mathrm{L}$ of the $\mathrm{Hu}-\mathrm{NoV}$ sample. The four types of prepared material surface were then inoculated with the viral suspension (approximately $6.60 \log _{10}$ genomic copies $/ \mu \mathrm{L}$ ). To enable absorption of the 
inoculated $\mathrm{Hu}-\mathrm{NoV}$ suspension on the surface, all agitated suspensions were incubated for $60 \mathrm{~min}$ at $18 \pm 3^{\circ} \mathrm{C}$ in a laminar flow hood. The virucidal activity of the SAEW spraying treatment was checked using a modified Quantitative Disk Carrier Test (ASTM E2197), a disinfectant testing protocol recognized worldwide. First, virucidal activity experiments examining spraying systems were performed in a $3.4 \mathrm{~m}^{3}$ chamber, in which air ventilation was blocked to facilitate full control of the airflow. The electric ULV sprayer was loaded with SAEW solution at $33.22 \mathrm{ppm} \mathrm{ACC,} \mathrm{pH} \mathrm{5.12,} \mathrm{and} 1123 \mathrm{mV}$ of ORP and used to generate sprayed droplets with a size of approximately $30 \pm 10 \mu \mathrm{m}$ at a $100-300 \mathrm{~mL} / \mathrm{min}$ spraying rate. The individual contaminated surfaces were sprayed with SAEW under the following conditions: spraying rate (100-300 $\mathrm{mL} / \mathrm{min})$, spraying time (2-10 s), and spraying distance $(0.5-2.5 \mathrm{~m})$. Thereafter, the disinfected surface was left for $5,10,20$, and $30 \mathrm{~min}$ to allow time for the SAEW droplets to inactivate viruses on the exposed surfaces. Triplicate spraying experiments were conducted for the evaluation of virucidal activity.

\subsection{Microbiological Analyses}

\subsubsection{Recovery of $\mathrm{Hu}-\mathrm{NoVs}$}

Elution, concentration, and optimal quantification of $\mathrm{Hu}-\mathrm{NoV}$ s from individual SAEW spray-disinfected surface samples were determined following the methodology of previous studies [20]. The optimized quantitative assay for elution and concentration of $\mathrm{Hu}-\mathrm{NoV}$ GI.6 and GII.4 is summarized in the flow diagram (Figure S1). Immediately following SAEW spray disinfection, an Enviro-Max Environmental sampling cotton swab kit (Puritan Medical Products Company LLC, Guilford, ME, USA) was used to recover Hu-NoV particles from each surface sample. Each surface was swabbed diagonally, vertically, and horizontally on both sides of the cotton swab, 15 times in each direction. Subsequently, $\mathrm{Hu}-\mathrm{NoV}$ particles were eluted using cotton swabs by repeatedly immersing in $20 \mathrm{~mL}$ of $0.14 \mathrm{M} \mathrm{NaCl}-0.05 \mathrm{M}$ glycine (pH 7.0) for $5 \mathrm{~min}$ in the transport tube at $18 \pm 3{ }^{\circ} \mathrm{C}$ with constant shaking (approximately $50 \mathrm{rpm}$ ). Each was then thoroughly mixed with a vortex machine for $60 \mathrm{~s}$. Subsequently, cotton swabs were squeezed against the inside wall of the tube, to release all liquid. Each eluate was placed into a $50 \mathrm{~mL}$ conical tube. Approximately $20 \mathrm{~mL}$ of the secondary suspension was added to the $20 \mathrm{~mL}$ of primary elution suspension.

\subsubsection{Optimized Quantification of $\mathrm{Hu}-\mathrm{NoV} \mathrm{s}$}

Hu-NoV particles were concentrated using the MBS technique. For the MBS assay, $100 \mu \mathrm{L}$ of magnetic bead suspension (final concentration: $10 \mathrm{mg} / \mathrm{mL}$ ) was added to $40 \mathrm{~mL}$ of the viral mixture suspension and agitated for $1 \mathrm{~h}$ at $18 \pm 3^{\circ} \mathrm{C}$. Magnetic beads with captured $\mathrm{Hu}-\mathrm{NoV}$ particles were isolated using a LifeSep magnetic separation stand (Sigma-Aldrich), and resuspended with $140 \mu \mathrm{L}$ of PBS. Following virucidal inactivation, RNA isolation and analysis were immediately conducted to avoid the effects induced by sample freezing.

Optimized quantification assays of viral particles from the SAEW spray-disinfected $\mathrm{Hu}-\mathrm{NoV}$ s were performed as previously reported. Specifically, an MBS/RT-qPCR assay was conducted following pretreatment with combined SLS (Sigma-Aldrich) and PMA (MBS/PMA/SLS/RT-qPCR) [11]. This method provides optimal conditions for quantification, while conferring minimal damage to intact $\mathrm{Hu}-\mathrm{NoV}$ particles. Each viral suspension treated with PMA dye was concentrated using MBS, immediately mixed further with $0.2 \mathrm{mM}$ PMA, and incubated in the dark at $4{ }^{\circ} \mathrm{C}$ for $5 \mathrm{~min}$, to allow dye penetration. A highpower LED light (45-W lamp) in a photo-activation system (PhAST Blue; GenIUL, Spain) was then used for irradiation of samples at a wavelength of $460 \mathrm{~nm}$ at $4{ }^{\circ} \mathrm{C}$ for $15 \mathrm{~min}$.

\subsubsection{Viral RNA Extraction and Quantitative RT-qPCR}

The Hu-NoV GI.6 and GII.4 RNA were purified using a QIAamp Min-Elute virus spin kit (Qiagen, Hilden, Germany), following the manufacturer's instructions. Approximately $60 \mathrm{~mL}$ of AVE buffer was used to elute Hu-NoV viral RNA, which was then used immediately to avoid RNA degradation associated with viral RNA freezing. Approximately $5 \mathrm{~mL}$ aliquots of each RNA suspension were subjected to one-step RT-qPCR using a QuantiTect 
Probe RT-PCR kit (Qiagen) and Real-Time PCR System (Applied Biosystems 7500 Fast system, Foster City, CA, USA).

For Hu-NoV GI.6 and GII4, one-step RT-qPCR was conducted using $5 \mu \mathrm{L}$ of viral RNA extracted from a total volume of $20 \mu \mathrm{L}$. The following cycling parameters were used: $50{ }^{\circ} \mathrm{C}$ for $600 \mathrm{~s}$, denaturation at $95{ }^{\circ} \mathrm{C}$ for $300 \mathrm{~s}, 45$ cycles of amplification with denaturation at $95^{\circ} \mathrm{C}$ for $10 \mathrm{~s}$, and combined annealing and extension at $60^{\circ} \mathrm{C}$ for $30 \mathrm{~s}$. For Hu-NoV GI-6, the TaqMan probe (JJV1P) sequence was FAM $5^{\prime}$-TGT.GGA.CAG.GAG·ATC.GCA.ATC.TC$3^{\prime}$ BHQ [10]. Hu-NoV GI primer (10 pmol each) sequences were $5^{\prime}-\mathrm{JJV} 1^{\mathrm{R}}$ TCC.TTA.GAC. GCC.ATC.ATC.AT-3' and JJV1 ${ }^{\mathrm{F}}$ 5' $^{\prime}$-GCC.ATG.TTC.CGI-TGG.ATG-3'. These primers were used to amplify a 96-base pair (bp) fragment of the $\mathrm{Hu}-\mathrm{NoV}$ GI polymerase gene. For $\mathrm{Hu}-$ NoV GII.4, the TaqMan probe (Ring ${ }^{2}, 10 \mathrm{mM}$ ) was FAM: 50-TGG.GAG.GGC.GAT.CGC. AAT.CT-30 BHQ. The Hu-NoV GII.4 primer sequences (10 mM each) were COG2 ${ }^{\mathrm{R}}$ : 50

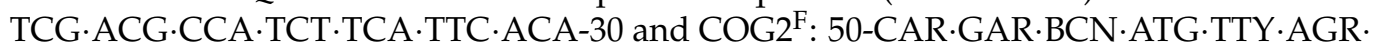
ATG.AG-30, which were used to amplify a 122-bp fragment of the Hu-NoV GII.4 [10].

\subsection{Statistical Analyses}

Trials of all experiments were carried out in triplicate. For the RT-qPCR assay, the experimental data were plotted using Minitab ${ }^{\circledR}$ statistical software and were expressed as $\log _{10}$ genomic copies $/ \mu \mathrm{L}$. For statistical analysis, the one-way ANOVA test in Minitab ${ }^{\circledR}$ statistical software and Duncan's multiple range test were used to compare differences between mean values. Moreover, ANOVA, in the Minitab ${ }^{\circledR}$ statistical software, was used to compare differences between mean values. A $p$-value $<0.05$ was defined as statistically significant. The experimental results were denoted as $\log _{10}$ genomic copies $/ \mu \mathrm{L}$. Regression analysis was conducted using the Sigma Plot software system, version 14.0 (San Jose, CA, USA).

\section{Results and Discussion}

\subsection{Pressure Distribution Measurement System}

The higher the pressure at the electric ULV sprayer inlet, the smaller the size of the spray particles, which has a significant effect on spray dispersion [21]. Moreover, a typical ULV sprayer produces thousands of droplets each second. Therefore, it is impractical to select the number of particles based on arithmetic calculations as a parameter for the optimum condition of the sprayer. Figure S2 presents a visualization of the pressure of the sprayer nozzle based on the treatment condition of the spraying rate $(100,200$, and $300 \mathrm{~mL} / \mathrm{min}$ ) derived from BBD.

\subsection{Changes in Physicochemical of SAEW after Spraying Treatment}

The physicochemical properties of the disinfectant can be altered owing to a rapid decrease in the cross-sectional area of SAEW droplets (average particle size $20-50 \mu \mathrm{m}$ aerosol mist) during the spraying process [22]. Table 3 shows the changes in physicochemical $\mathrm{pH}$, ORP, and ACC of the original SAEW and sprayed SAEW. Overall, the $\mathrm{pH}$ and ACC of SAEW changed significantly with increasing distance between the spray nozzle and contact surface, whereas the ORP values remained stable at $1.5 \mathrm{~m}$. According to Zhao et al., spraying treatment increases the $\mathrm{pH}$ values by approximately 1.0 when the ACC is decreased by approximately $70 \%$, making the SAEW slightly more basic [23]; it is speculated that the physiochemical properties of SAEW are altered owing to the evaporation of chlorine gas. However, despite the observed changes in the $\mathrm{pH}$ and ACC values of the sprayed SAEW, all tested SAEW samples fell within the range of typical SAEW properties (20 to $80 \mathrm{mg} / \mathrm{L}$ ACC, approximately $1000 \mathrm{mV}$ ORP, and 5.0 to 6.0 near-neutral pH). Hence, sprayed SAEW, with altered shape and smaller droplets, maintains its virucidal effect. 
Table 3. Physicochemical properties of slightly acidic electrolyzed water samples collected after spraying.

\begin{tabular}{|c|c|c|c|c|c|c|}
\hline \multirow{2}{*}{ Property } & \multirow{2}{*}{$\begin{array}{c}\text { Original } \\
\text { SAEW }\end{array}$} & \multicolumn{5}{|c|}{ SAEW Captured from a Distance (m) } \\
\hline & & 0.5 & 1 & 1.5 & 2 & 2.5 \\
\hline $\mathrm{pH}$ & $5.12 \pm 0.01^{\mathrm{a}}$ & $5.31 \pm 0.02^{b}$ & $5.38 \pm 0.02^{b c}$ & $5.45 \pm 0.03^{c}$ & $5.59 \pm 0.01^{\mathrm{d}}$ & $5.61 \pm 0.01^{d}$ \\
\hline ORP (mV) & $1123 \pm 7^{\mathrm{a}}$ & $1026 \pm 5^{\mathrm{a}}$ & $1007 \pm 13^{a}$ & $1001 \pm 9^{a}$ & $983 \pm 11^{b}$ & $981 \pm 7^{b}$ \\
\hline $\mathrm{ACC}(\mathrm{ppm})$ & $34.22 \pm 0.31^{\mathrm{a}}$ & $33.58 \pm 0.37^{a}$ & $32.93 \pm 0.34^{\mathrm{ab}}$ & $30.91 \pm 0.22^{b}$ & $29.18 \pm 0.29^{c}$ & $29.17 \pm 0.22^{d}$ \\
\hline
\end{tabular}

${ }^{\mathrm{a}-\mathrm{d}}$ Different lower-case letters indicate statistically significant differences between SAEW samples for the same physicochemical properties, $p<0.05$.

\subsection{Model Development and Statistical Analysis}

The BBD-based experimental results are presented in Table 4 along with a comparison of the predicted and observed color response values $\left(\mathrm{F}\left(X_{C}\right)\right)$ after spraying the SAEWcitric acid mixture onto $\mathrm{pH}$-sensitive indicator paper. Figure $\mathrm{S} 3$ shows a visualization of $\mathrm{pH}$-sensitive indicator papers, one of which was randomly selected from each spray treatment trial. Additionally, it is possible to observe changes in the R (red), G (green), and $\mathrm{B}$ (blue) values of the $\mathrm{pH}$-sensitive indicator papers, according to the dispersion pattern. The regression equation (Equation (5)), used to compare changes in the $\mathrm{F}\left(X_{C}\right)$ of the $\mathrm{pH}$-sensitive indicator paper in terms of the coded values of variables is as follows:

$$
\begin{gathered}
\mathrm{F}\left(X_{C}\right)=-0.373+0.00724 X_{1}+0.0337 X_{2}+0.657 X_{3}+0.000007 X_{1} X_{1}+0.00223 X_{2} X_{2}-0.1614 X_{3} X_{3}+ \\
0.000714 X_{1} X_{2}-0.003173 X_{1} X_{3}-0.0272 X_{2} X_{3}
\end{gathered}
$$

where $X_{1}, X_{2}$, and $X_{3}$ are the uncoded values of the spraying rate $(\mathrm{mL} / \mathrm{min})$, spraying time $(\mathrm{s})$, and spraying distance $(\mathrm{m})$, respectively.

Table 4. Matrix design results for the experiments performed according to the Box-Behnken experimental design for the color response values $(\mathrm{F}(\mathrm{Xc}))$ of the sprayed SAEW droplet dispersion and

\begin{tabular}{|c|c|c|c|c|c|}
\hline \multirow{2}{*}{ Source } & \multirow{2}{*}{$\mathrm{DF}^{(1)}$} & \multicolumn{4}{|c|}{$\mathbf{F}\left(X_{C}\right)$} \\
\hline & & Adj SS (2) & Adj MS ${ }^{(3)}$ & F-Value & $p$-Value \\
\hline Regression & 9 & 6.82322 & 0.75814 & 39.11 & 0.000 \\
\hline $\mathrm{e}$ & 3 & 5.93777 & 1.97926 & 102.09 & 0.000 \\
\hline$X_{1}$ & 1 & 1.29191 & 1.29191 & 66.64 & 0.000 \\
\hline$X_{2}$ & 1 & 1.51548 & 1.51548 & 78.17 & 0.000 \\
\hline$X_{3}$ & 1 & 3.13038 & 3.13038 & 161.47 & 0.000 \\
\hline Square & 3 & 0.10930 & 0.03643 & 1.88 & 0.251 \\
\hline$X_{1} X_{1}$ & 1 & 0.01733 & 0.01733 & 0.89 & 0.388 \\
\hline$X_{2} X_{2}$ & 1 & 0.00472 & 0.00472 & 0.24 & 0.643 \\
\hline$X_{3} X_{3}$ & 1 & 0.09621 & 0.09621 & 4.96 & 0.076 \\
\hline Interaction & 3 & 0.77615 & 0.25872 & 13.34 & 0.008 \\
\hline$X_{1} X_{2}$ & 1 & 0.32596 & 0.32596 & 16.81 & 0.009 \\
\hline$X_{1} X_{3}$ & 1 & 0.40271 & 0.40271 & 20.77 & 0.006 \\
\hline$X_{2} X_{3}$ & 1 & 0.04749 & 0.04749 & 2.45 & 0.178 \\
\hline Residual Error & 5 & 0.09693 & 0.01939 & & \\
\hline Lack of Fit & 3 & 0.04933 & 0.01644 & 0.69 & 0.637 \\
\hline Pure Error & 2 & 0.04761 & 0.02380 & & \\
\hline$R^{2}$ & & \multicolumn{4}{|c|}{98.60} \\
\hline
\end{tabular}
contact pattern.

${ }^{1)} \mathrm{DF}$, degrees of freedom; ${ }^{(2)}$ Adj SS, adjusted sum of square; ${ }^{(3)}$ Adj MS, adjusted mean square.

The color response value parameters for the dispersion pattern of SAEW sprayed particles were estimated. According to the ANOVA results (Table 4), the F-value < Prob was less than 0.05 with an F-value of 39.11, indicating an acceptable model fit and that the three variables had a prominent effect on the dispersion pattern of SAEW sprayed particles. Both the F- and $p$-values demonstrate the significance of variable coefficients. That is, lower $p$-values and higher F-values indicate that a more important contribution 
was made by the corresponding model term toward the response variable [24]. As a result, the order in which the test variables affected the response was as follows: spraying distance $(\mathrm{m})>$ spraying time $(\mathrm{s})>$ rate $(\mathrm{mL} / \mathrm{min})$. With respect to the dispersion pattern of SAEW sprayed particles, the spraying distance $(\mathrm{m})$ had the most significant influence on the color response parameters (F-value: 161.47$)$, whereas both the spraying rate $(\mathrm{mL} / \mathrm{min})$ and spraying time (s) had a less significant effect (F-value: 66.64 and 78.17, respectively). The parameters that impacted the interaction strength were the spraying rate and spraying distance ( $p$-value: 0.006$)$. However, the relationship between the spraying distance and time was not significant ( $p$-value: 0.178 ), suggesting that the uniformity of sprayed SAEW particle dispersion does not impact the response, even if the spray time increases with increased spray distance. Hence, the spraying distance and rate have a greater impact than spraying time on ensuring an even diffusion of SAEW spray particles on the target surface. That is, the efficiency of SAEW spray particle dispersion can be increased by regulating spraying distance and rate.

If the $p$-value for the 'lack of fit' is $<0.05$, the predicted model is inadequate, whereas if it is greater than 0.05 , the obtained model is appropriate [25]. In our study, the $p$-value related to lack of fit in the obtained model was 0.637 , and the model obtained from the ANOVA procedure was found to be acceptable [25]. The significance of the selected quadratic model was calculated using regression coefficient $\left(\mathrm{R}^{2}\right)$ values, which revealed high coefficients $(0.986)$ for the uniformity of SAEW spray particle dispersion obtained from $\mathrm{F}\left(X_{C}\right)$ values. Furthermore, the high $\mathrm{R}^{2}$ obtained for the comparison of the predicted $\mathrm{F}\left(\mathrm{X}_{C}\right)$ and experimental $F\left(X_{C}\right)$ values $\left(R^{2}=0.983\right.$; Figure $\left.2 a\right)$ demonstrated that this quadratic model could be applied to predict optimized experimental conditions for a SAEW spray disinfection treatment. The $\mathrm{R}^{2}(0.983)$ for the SAEW spray particle dispersion implied that only $1.7 \%$ variation could not be explained by the obtained model.

In addition, the Pareto analysis (Figure 2b) identified the SAEW disinfection variables (spraying rate, time, and distance) that have the greatest impact on the efficiency and reliability of a SAEW spray disinfection treatment, which were illustrated and selected based on the data from the experimental results in Table 4. According to Secula et al., the Pareto chart, demonstrating the absolute value of the standardized influencing factors, is used to define the importance and magnitude of the effects among the independent parameter effect, second-order effect, and interaction effect [26]. Moreover, the Pareto chart indicates the significance of each variable investigated in the experimental data and illustrates the primary effects of the factors, to be ranked in order of their significance [25]. The vertical line in the Pareto chart shows a table value of 2.57 with a $95 \%$ confidence level, whereas the horizontal bar chart indicates the calculated $t$-values. According to this comprehensive statistical analysis, a quadratic model could be applied to predict the optimized experimental conditions for SAEW spray treatment.

\subsection{Response Surface Plots for Parameter Optimization}

To establish optimized parameters of SAEW spray disinfection treatment, a 3D response surface plot was used to predict the interaction between a pair of factors, while fixing all other parameters. The interactions between spraying rate and spraying time, spraying rate and spraying distance, and spraying time and spraying distance for the dispersion of SAEW sprayed particles using an electric ULV sprayer are illustrated in Figure $3 a-c$, whereas Figure $3 d$ presents a graph of the optimal conditions for the three parameters with maximum color response values $\left(\mathrm{F}\left(X_{C}\right)\right)$, indicating that the spray particles were effectively dispersed. The optimized $F\left(X_{C}\right)$ values for the three process parameters were acquired using the mathematical multiple optimization method; namely, a spraying rate of $218 \mathrm{~mL} / \mathrm{min}$, spraying time of $4.9 \mathrm{~s}$, and spraying distance of $0.9 \mathrm{~m}$. These optimum parameters provided a predicted $\mathrm{F}\left(X_{C}\right)$ of 1.3079 and a specific $\mathrm{F}\left(X_{C}\right)$ of 1.311 for the dispersion pattern of SAEW sprayed particles using an electric ULV sprayer. Both results are the same as the predicted values, within numerical error, confirming the suitability and validity of the predicted model. When considering the efficiency of spray disinfection 
treatment, it has been recognized that the amount of time that the sprayed disinfectant remains on the contaminant (i.e., contact time) is the most important factor [27]. Indeed, contact time is clearly indicated on the label of liquid disinfectants registered with the US Environmental Protection Agency (EPA) [28]. Thus, spray sterilization can be defined as effective only when direct contact between the disinfectant and microorganisms occurs for a sufficient length of time. The lack of scientific data to support the required contact time between disinfectants and microorganisms may account for the persistent issues regarding the reliability of spray sterilization techniques. As such, we believe that our findings advance the current understanding regarding the optimal conditions associated with the application of SAEW mist to contaminants on environmental surfaces. Moreover, we have demonstrated that a uniform and complete dispersion of the disinfectant particles sprayed from a nebulizer ensures sufficient contact time.

\subsection{Validation of MBS/PMA/SLS Pretreatment Combined with RT-qPCR Assay}

In the present study, MBS/PMA/SLS and RT-qPCR were the methods employed to quantitatively and qualitatively investigate the viability of $\mathrm{Hu}-\mathrm{NoV}$ s following disinfection with SAEW. From the point of view of false-positive outcomes caused by the nonspecific amplification of inactivated and infectious viruses, the RT-qPCR assay produced cycle threshold (Ct) values for both Hu-NoV GI.6 and GII.4 after treatment with SAEW (ORP of $1123 \mathrm{mV}$, pH of 5.12, and ACC of $33.22 \mathrm{ppm}$ ), and both $\mathrm{Hu}-\mathrm{NoVs}$ were amplified at a value of approximately $40 \mathrm{Ct}$ by MBS/PMA/SLS/RT-qPCR (Figure S4). Our findings demonstrated that RT-qPCR, without PMA-SLS, amplified target viruses after SAEW treatment, resulting in false-positive outcomes, despite an adequate inactivation treatment.

Although RT-qPCR assays are widely used to quantify targeted viral particles, owing to their short assay time, sensitivity, and specificity, certain technical obstacles exist when applying nucleic acid-based detection assays to the assessment of viral particles after chemical inactivation. One such obstacle is their inability to distinguish noninfectious from infectious viruses in disinfected viral samples. Conversely, specific MBS has been shown to effectively help avoid these pitfalls [29]. Indeed, MBS technology has been reported to increase virus concentration and detection sensitivity $[30,31]$. In addition, numerous studies have reported that pretreatment of samples with intercalating dyes (PMA or ethidium monoazide) can improve the discrimination of intact viral particles. As such, these more advanced analysis techniques are regularly adopted to eliminate the false-positive results caused by nonspecific binding to magnetic beads [32-34]. Furthermore, SLS, an anionic surfactant, has been shown to facilitate the entry of intercalating dyes into injured viral capsid proteins, thereby enhancing the differentiation of noninfectious and infectious viral particles [35,36]. Hence, MBS/PMA/SLS treatment combined with RT-qPCR, as performed in this study, is believed to be a suitable and reliable strategy for distinguishing among dead, damaged, and intact viral particles following SAEW spray treatment.

\subsection{Virucidal Effect of the Optimal Spraying Treatment}

To evaluate the validity of the given quadratic model based on the BBD, virucidal tests were performed under optimized conditions (Figure 4). For Hu-NoV GI.6, the virucidal efficacies on PVC, stainless steel, ceramic tile, and glass surfaces at optimum conditions for a 30-min treatment were $4.66 \pm 0.11,5.11 \pm 0.23,3.57 \pm 0.19$, and $4.54 \pm 0.27$ log reduction, respectively. Similarly, Hu-NoV GII.4, SAEW disinfection under optimal conditions with a 30-min treatment had $\log$ reduction values of $4.89 \pm 0.31,5.06 \pm 0.18,3.49 \pm 0.22$, and $4.89 \pm 0.27$ on the four surfaces, respectively. More specifically, following exposure to sprayed SAEW virucidal treatment for more than $5 \mathrm{~min}$, a greater than 3 log viral reduction was achieved in most treatment groups, apart for Hu-NoV GI.6 inoculated on PVC and ceramic tile surfaces and Hu-NoV GII.4 inoculated on ceramic tile surfaces. Furthermore, sprayed PBS droplets, which served as the negative control, elicited no inactivation effect against either $\mathrm{Hu}-\mathrm{NoV}$ on the four surfaces. 


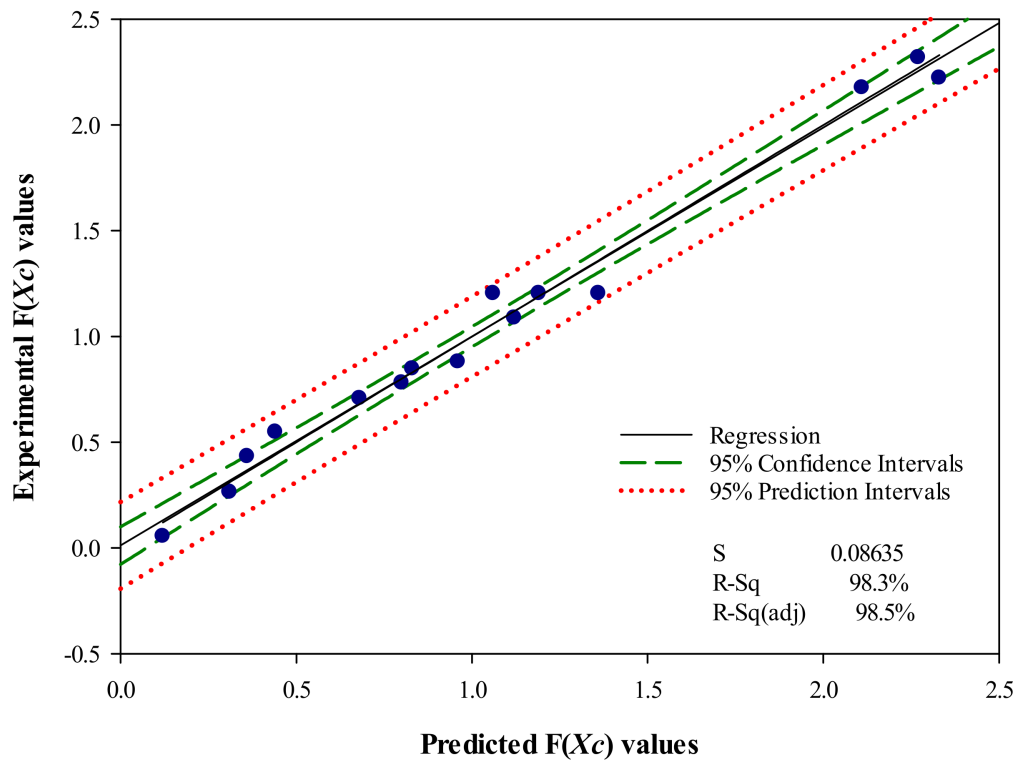

(a)

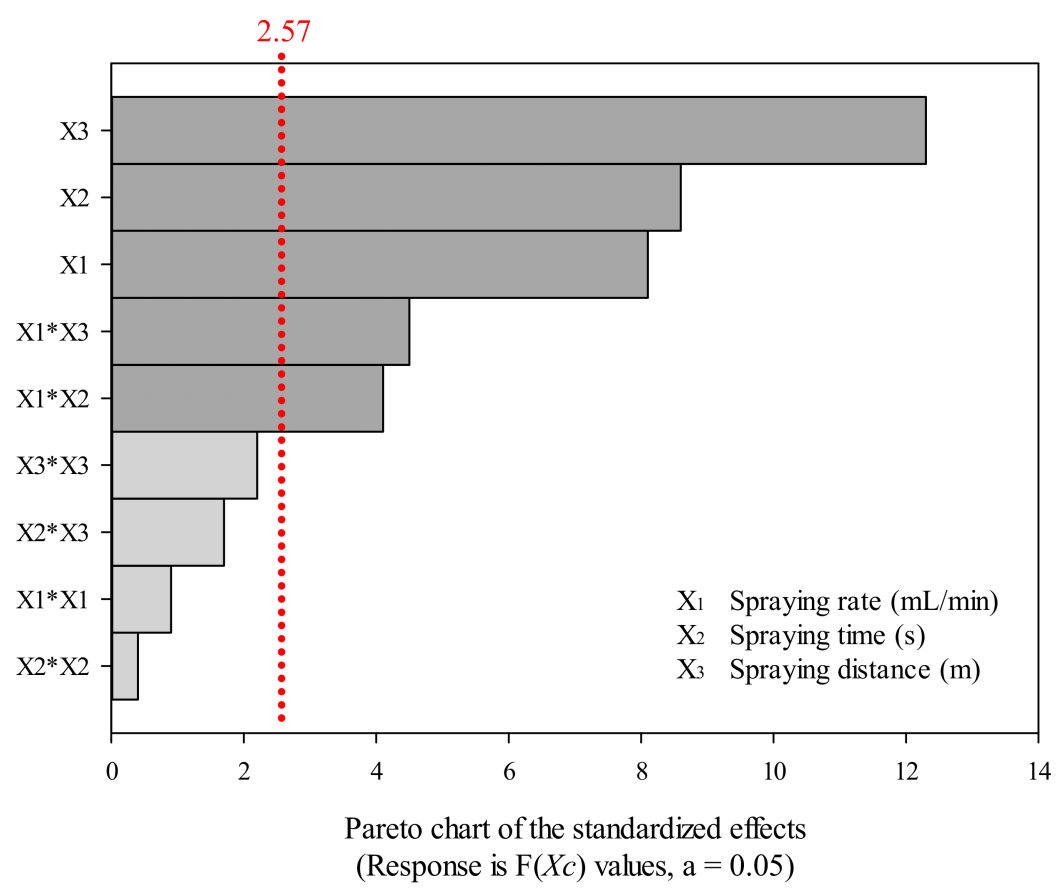

(b)

Figure 2. (a) Fitted line plot for the predicted and experimental values of the color response value $\left(\mathrm{F}\left(\mathrm{X}_{\mathrm{C}}\right)\right)$, $(\mathbf{b})$ standardized Pareto chart for the color response value $\left(\mathrm{F}\left(\mathrm{X}_{\mathrm{C}}\right)\right)$. 


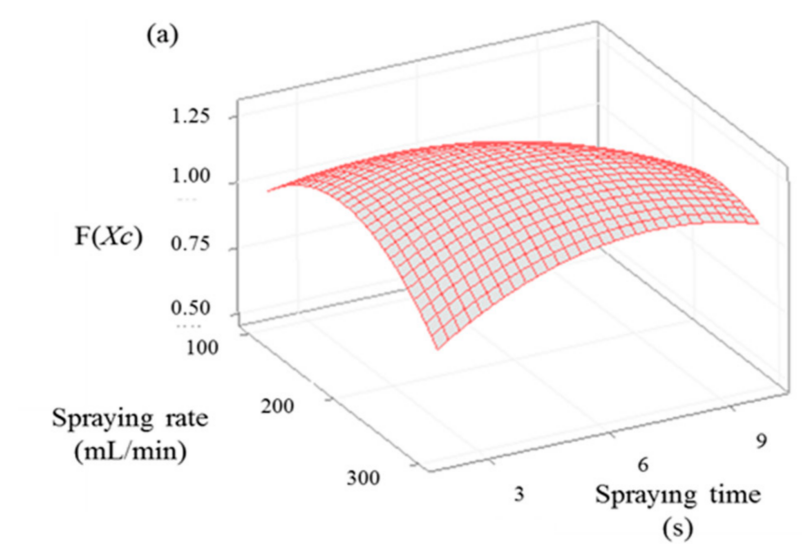

(d)

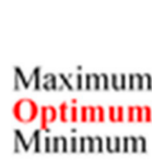

Spraying rate $(\mathrm{mL} / \mathrm{min})$

Minimum

300

300
100

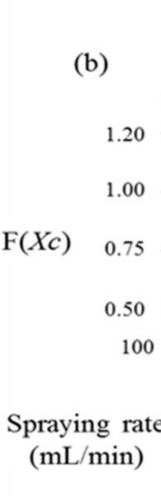

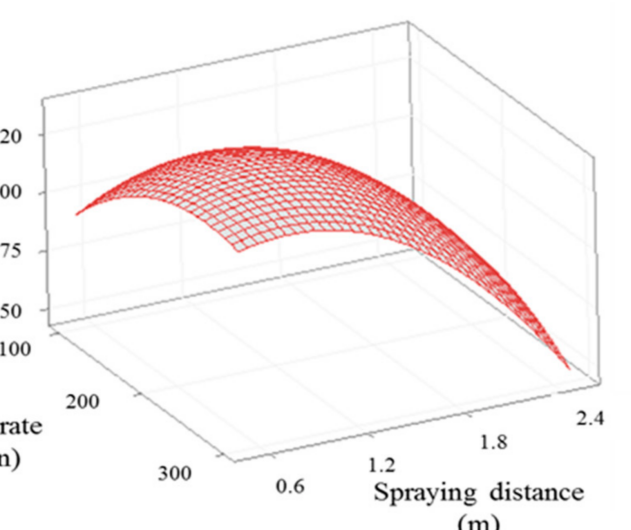

(m)

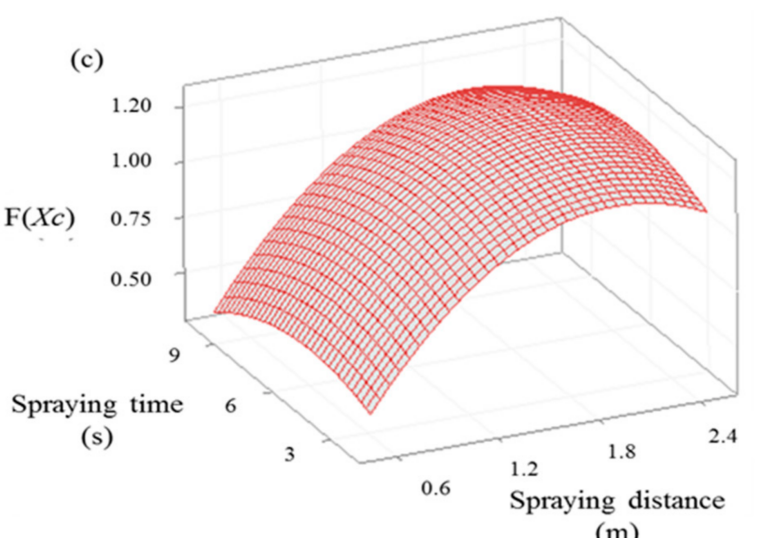

$(\mathrm{m})$

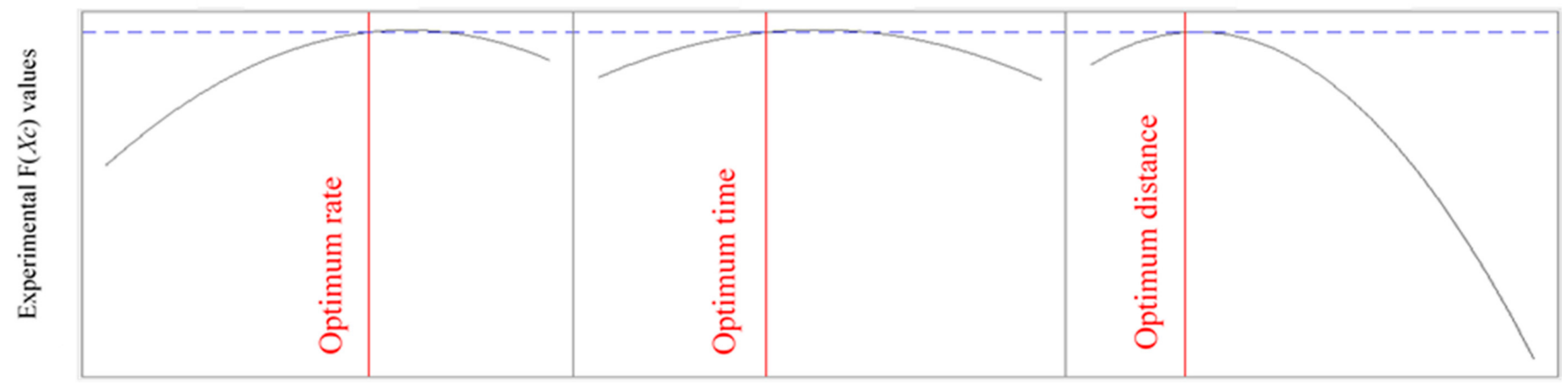

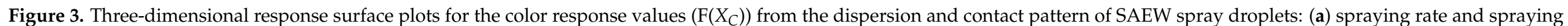

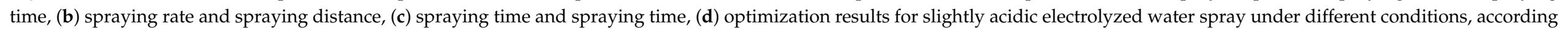
to the response surface methodology. Multiple optimization graphs of experimental color response values $\left(\mathrm{F}\left(X_{C}\right)\right)$. 

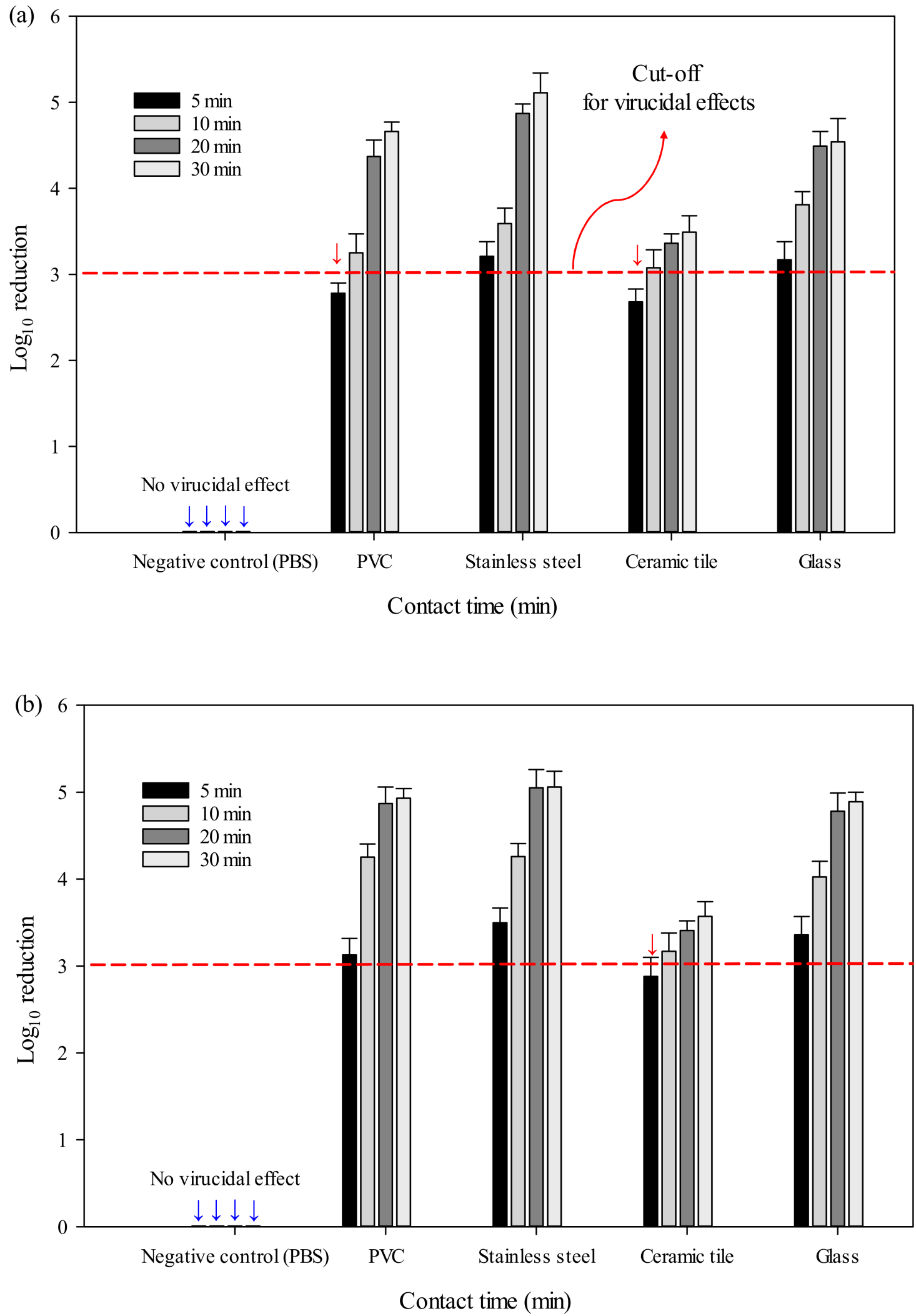

Figure 4. Reduction values of (a) Hu-NoV GI.6 and (b) GII.4 titers after disinfection with slightly acidic electrolyzed water spray under optimal treatment conditions on PVC, stainless steel, ceramic tile, and glass surfaces. 
For NoVs on various material-specific surfaces, the magnitude of virus reduction was dependent on the exposure time after spray treatment. These results indicate that they were derived by considering the norovirus control effect and the economic effect of spray sterilization. Interestingly, the virucidal effect of optimal SAEW disinfection on both $\mathrm{Hu}-\mathrm{NoVs}$ was lower on ceramic tiles than on other surfaces, likely owing to the high water absorption of ceramic tiles, which is believed to obstruct the virucidal effect by not allowing sufficient time for the spray particles of SAEW to react with the viral particles. Marks et al. suggested that a chemical disinfectant could effectively disinfect surfaces carrying viral particles if it causes a $3 \log 10$ value reduction in virus population, taking into consideration the amount of virus shed into the environment [37]. Hence, our findings demonstrated that SAEW disinfection treatment under optimal conditions for $10 \mathrm{~min}$ or more achieves acceptable levels of $\mathrm{Hu}-\mathrm{NoV}$ decontamination on four common surfaces.

As the COVID-19 pandemic continues, there is a growing consensus that sufficient disinfection and the prevention of surfaces from being contaminated with pathogenic viral particles is essential, to slow the spread of this virus in complex multi-facilities, schools, hotels, nursing homes, and hospitals. ULV sprayer disinfection represents an effective approach for preventing surface-based viral particle transmission. However, although this method offers certain benefits, the efficiency of other techniques, particularly for the inactivation of $\mathrm{Hu}-\mathrm{NoV}$ s on various surfaces, has not been adequately investigated. In fact, to date, a comprehensive assessment of the optimal models for ULV sprayer disinfectants is lacking, particularly regarding the optimal physics of these sprayers and surface characteristics to ensure inactivation of Hu-NoVs. Nasr et al. suggested that disinfection efficiency is affected by several parameters, including spray droplet size, spray pressure, disinfectant contact time, disinfectant droplet distribution, and distance from surfaces; all of which must be considered when seeking to verify the effectiveness of spray disinfection [38].

\section{Conclusions}

The fomite transmission of $\mathrm{Hu}-\mathrm{NoV}$ s, a common human pathogen, requires decontamination techniques for prevention and control. Optimized experimental conditions for SAEW spraying (spraying rate: $218 \mathrm{~mL} / \mathrm{min}$, spraying time: $4.9 \mathrm{~s}$, and spraying distance: $0.9 \mathrm{~m}$ ) show that SAEW spray disinfection (ORP of $1123 \mathrm{mV}$, $\mathrm{pH}$ range of 5.12, and ACC of $33.22 \mathrm{ppm}$ ) is efficient for the inactivation of Hu-NoVs on fomite surfaces. We believe that the utilization of a ULV sprayer loaded with SAEW can provide a successful decontamination of surfaces. Furthermore, this technique enables the control of $\mathrm{Hu}-\mathrm{NoV}$ and prevents it from being transmitted via environmental surface exposure. However, our experimental results are not representative of all commercially available electric ULV sprayers, and the optimal disinfection conditions for each spray sterilizer product may vary. Thus, virucidal evaluation of various electric ULV sprayer products must be performed in follow-up studies. Collectively, the findings of this study may have a significant impact on the strategic control practices of infectious disease transmission and in the prevention of Hu-NoV outbreaks.

Supplementary Materials: The following are available online at https://www.mdpi.com/article/10 .3390 /ijerph181910183/s1, Figure S1: Flow diagram of the analytical methods used for the quantitative evaluation of the virucidal efficacy for Hu-NoVs.; Figure S2: Visualization of the sprayer nozzle pressure based on the treatment condition of the spraying rate (a) 100, (b) 200, and (c) $300 \mathrm{~mL} / \mathrm{min}$.; Figure S3: Visualization of the dispersion and contact pattern of SAEW spray droplets based on BBD treatment conditions (15 run set).; Figure S4: Comparison of RT-qPCR assay with MBS/PMA/SLS/RTqPCR for the evaluation of inactivation of disinfected NoV GI.6 and GII.4.

Author Contributions: Conceptualization, H.-W.L. and J.-H.H.; methodology, S.-R.Y. and H.S.; data curation, H.-W.L. and B.P.; writing-original draft preparation, H.-W.L.; writing-review and editing, J.-H.H.; supervision, J.-H.H. All authors have read and agreed to the published version of the manuscript. 
Funding: This research was funded by the World Institute of Kimchi, grant number KE2102-2, which was funded by the Ministry of Science and ICT, Republic of Korea.

Institutional Review Board Statement: Not applicable.

Informed Consent Statement: Not applicable.

Data Availability Statement: The datasets used and/or analyzed during the current study are available from the corresponding author on reasonable request.

Conflicts of Interest: The authors declare no conflict of interest.

\section{References}

1. Hartmann, E.M.; Colquhoun, D.R.; Schwab, K.J.; Halden, R.U. Absolute quantification of norovirus capsid protein in food, water, and soil using synthetic peptides with electrospray and MALDI mass spectrometry. J. Hazard. Mater. 2015, 286, 525-532. [CrossRef]

2. $\quad$ Pires, S.M.; Fischer-Walker, C.L.; Lanata, C.F.; Devleesschauwer, B.; Hall, A.J.; Kirk, M.D.; Duarte, A.S.; Black, R.E.; Angulo, F.J. Aetiology-specific estimates of the global and regional incidence and mortality of diarrhoeal diseases commonly transmitted through food. PLoS ONE 2015, 10, e0142927. [CrossRef]

3. Lopman, B.A. Global Burden of Norovirus and Prospects for Vaccine Development. CDC Foundation 2015. Available online: https:/ / www.cdc.gov / norovirus/downloads/global-burden-report.pdf (accessed on 10 September 2021).

4. de Graaf, M.; van Beek, J.; Koopmans, M.P. Human norovirus transmission and evolution in a changing world. Nat. Rev. Microbiol. 2016, 14, 421-433. [CrossRef]

5. Kirby, A.E.; Streby, A.; Moe, C.L. Vomiting as a symptom and transmission risk in norovirus illness: Evidence from human challenge studies. PLoS ONE 2016, 11, e0143759. [CrossRef]

6. Bonifait, L.; Charlebois, R.; Vimont, A.; Turgeon, N.; Veillette, M.; Longtin, Y.; Jean, J.; Duchaine, C. Detection and quantification of airborne norovirus during outbreaks in healthcare facilities. Clin. Infect. Dis. 2015, 61, 299-304. [CrossRef]

7. Djebbi-Simmons, D.; Alhejaili, M.; Janes, M.; King, J.; Xu, W. Survival and inactivation of human norovirus GII.4 Sydney on commonly touched airplane cabin surfaces. AIMS Public Health 2020, 7, 574-586. [CrossRef] [PubMed]

8. Honda, Y. Improvement of the electrolysis equipment and application of slightly acidic electrolyzed water for dairy farming. J. Jpn. Soc. Agric. Mach. 2003, 65, 27-29. [CrossRef]

9. Moorman, E.; Montazeri, N.; Jaykus, L.A. Efficacy of neutral electrolyzed water for inactivation of human norovirus. Appl. Environ. Microbiol. 2017, 83, e00653-17. [CrossRef] [PubMed]

10. Lee, H.W.; Lee, H.M.; Yoon, S.R.; Kim, S.H.; Ha, J.H. Pretreatment with propidium monoazide/sodium lauroyl sarcosinate improves discrimination of infectious waterborne virus by RT-qPCR combined with magnetic separation. Environ. Pollut. 2018, 233, 306-314. [CrossRef] [PubMed]

11. Moon, E.W.; Lee, H.W.; Rok, J.H.; Ha, J.H. Photocatalytic inactivation of viral particles of human norovirus by Cu-doped TiO 2 non-woven fabric under UVA-LED wavelengths. Sci. Total Environ. 2020, 749, 141574. [CrossRef] [PubMed]

12. Otter, J.A.; Yezli, S.; Perl, T.M.; Barbut, F.; French, G.L. The role of 'no-touch' automated room disinfection systems in infection prevention and control. J. Hosp. Infect. 2013, 83, 2. [CrossRef]

13. Clausen, P.A.; Frederiksen, M.; Sejbæk, C.S.; Sørli, J.B.; Hougaard, K.S.; Frydendall, K.B.; Carøe, T.K.; Flachs, E.M.; Meyer, H.W.; Schlünssen, V.; et al. Chemicals inhaled from spray cleaning and disinfection products and their respiratory effects. A comprehensive review. Int. J. Hyg. Environ. Health 2020, 229, 113592. [CrossRef]

14. Oh, S.W.; Gray, P.M.; Dougherty, R.H.; Kang, D.H. Aerosolization as novel sanitizer delivery system to reduce food-borne pathogens. Lett. Appl. Microbiol. 2005, 41, 56-60. [CrossRef]

15. Rutala, W.A.; Weber, D.J. Updated 2019. Health Infection Control Practices Advisory Committee, Guideline for Disinfection and Sterilisation in Healthcare Facilities, 2008. Available online: https://www.cdc.gov/infectioncontrol/guidelines/disinfection/ (accessed on 10 September 2021).

16. Park, H.; Hung, Y.-C.; Chung, D. Effects of chlorine and $\mathrm{pH}$ on efficacy of electrolyzed water for inactivating Escherichia coli O157:H7 and Listeria monocytogenes. Int. J. Food Microbiol. 2004, 91, 13-18. [CrossRef]

17. Gregersen, J.P.; Roth, B. Inactivation of stable viruses in cell culture facilities by peracetic acid fogging. Biologicals 2012, 40, 282-287. [CrossRef]

18. Ferreira, S.L.; Bruns, R.E.; Ferreira, H.S.; Matos, G.D.; David, J.M.; Brandao, G.C.; Silva, E.G.; Portugal, L.A.; Reis, P.S.; Souza, A.S.; et al. Box-Behnken design: An alternative for the optimization of analytical methods. Anal. Chim. Acta 2007, 597, 179-186. [CrossRef]

19. Giannakourou, M.C.; Taoukis, P.S. Systematic application of time temperature integrators as tools for control of frozen vegetable quality. J. Food Sci. 2002, 67, 2221-2228. [CrossRef]

20. Ha, J.H.; Choi, C.; Lee, H.J.; Ju, I.S.; Lee, J.S.; Ha, S.D. Efficacy of chemical disinfectant compounds against human norovirus. Food Control. 2016, 59, 524-529. [CrossRef]

21. Block, M.S.; Rowan, B.G. Hypochlorous acid: A review. J. Oral Maxillofac. Surg. 2020, 78, 1461-1466. [CrossRef] 
22. Mostert, J.; Buys, E. Hygiene by design. In Advanced Dairy Science and Technology; Britz, T.J., Robinson, R.K., Eds.; Wiley: New York, NY, USA, 2008; pp. 75-120.

23. Zhao, Y.; Xin, H.; Zhao, D.; Zheng, W.; Tian, W.; Ma, H.; Liu, K.; Hu, H.; Wang, T.; Soupir, M.; et al. Free chlorine loss during spraying of membraneless acidic electrolyzed water and its antimicrobial effect on airborne bacteria from poultry house. Ann. Agric. Environ. Med. 2014, 21, 249. [CrossRef]

24. Feilizadeh, M.; Mul, G.; Vossoughi, M.E. E. coli inactivation by visible light irradiation using a Fe-Cd/TiO 2 photocatalyst: Statistical analysis and optimization of operating parameters. Appl. Catal. B Environ. 2015, 168, 441-447. [CrossRef]

25. Silva, E.K.; Alvarenga, V.O.; Bargas, M.A.; Sant'Ana, A.S.; Meireles, M.A.A. Non-thermal microbial inactivation by using supercritical carbon dioxide: Synergic effect of process parameters. J. Supercrit. Fluids 2018, 139, 97-104. [CrossRef]

26. Secula, M.S.; Cretescu, I.; Cagnon, B.; Manea, L.R.; Stan, C.S.; Breaban, I.G. Fractional factorial design study on the performance of gac-enhanced electrocoagulation process involved in color removal from dye solutions. Materials 2013, 6, 2723-2746. [CrossRef]

27. Rutala, W.A.; Weber, D.J. Surface disinfection: Treatment time (wipes and sprays) versus contact time (liquids). Infect. Control Hosp. Epidemiol. 2018, 39, 329-331. [CrossRef] [PubMed]

28. Rutala, W.A.; Weber, D.J. Selection of the ideal disinfectant. Infect. Control Hosp. Epidemiol. 2014, 35, 855-865. [CrossRef] [PubMed]

29. Morton, V.; Jean, J.; Farber, J.; Mattison, K. Detection of noroviruses in ready-to-eat foods by using carbohydrate-coated magnetic beads. Appl. Environ. Microbiol. 2009, 75, 4641-4643. [CrossRef] [PubMed]

30. Tian, M.; Jin, M.; Xiem, H.; Duan, Z.; Jiang, X.; Fang, Z. Outbreak studies of a GII-3 and a GII-4 norovirus revealed an association between HBGA phenotypes and viral infection. J. Med. Virol. 2008, 80, 1296-1301. [CrossRef]

31. Pan, L.; Zhang, Q.; Li, X.; Tian, P. Detection of human norovirus in cherry tomatoes, blueberries and vegetable salad by using a receptor-binding capture and magnetic sequestration (RBCMS) method. Food Microbiol. 2012, 30, 420-426. [CrossRef]

32. Escudero-Abarca, B.I.; Rawsthorne, H.; Goulter, R.M.; Suh, S.H.; Jaykus, L.A. Molecular methods used to estimate thermal inactivation of a prototype human norovirus: More heat resistant than previously believed? Food Microbiol. 2014, 41, 91-95. [CrossRef]

33. Moreno, L.; Aznar, R.; Sánchez, G. Application of viability PCR to discriminate the infectivity of hepatitis A virus in food samples. Int. J. Food Microbiol. 2015, 201, 12. [CrossRef]

34. Randazzo, W.; López-Gálvez, F.; Allende, A.; Aznar, R.; Sánchez, G. Evaluation of viability PCR performance for assessing norovirus infectivity in fresh-cut vegetables and irrigation water. Int. J. Food Microbiol. 2016, 229, 10. [CrossRef]

35. Yang, X.; Badoni, M.; Gill, C.O. Use of propidium monoazide and quantitative PCR for differentiation of viable Escherichia coli from E. coli killed by mild or pasteurizing heat treatments. Food Microbiol. 2011, 28, 1478-1482. [CrossRef]

36. Wang, H.; Gill, C.O.; Yang, X. Use of sodium lauroyl sarcosinate (sarkosyl) in viable real-time PCR for enumeration of Escherichia coli. J. Microbiol. Methods 2014, 98, 89-93. [CrossRef]

37. Marks, P.J.; Vipond, I.B.; Carlisle, D.; Deakin, D.; Fey, R.E.; Caul, E.O. Evidence for airborne transmission of Norwalk-like virus (NLV) in a hotel restaurant. Epidemiol. Infect. 2000, 124, 481-487. [CrossRef]

38. Nasr, G.; Whitehead, A.; Yule, A. Fine sprays for disinfection within healthcare. Int. J. Multiphys. 2012, 6, 149-166. [CrossRef] 